\title{
A comparative study of disopyramide and procainamide in the treatment of myotonia in myotonic dystrophy
}

\author{
MICHAEL FINLAY \\ From the Department of Neurology, Royal Hallamshire Hospital, Sheffield
}

SUMMARY Ten patients with myotonic dystrophy were allocated at random to treatment with disopyramide and procainamide in a cross-over trial. Disopyramide was found to be at least as effective as procainamide in the relief of myotonia; and two patients who could not tolerate procainamide both tolerated disopyramide.

Myotonic dystrophy was first described by Steinert ${ }^{1}$ and the clinical features have been reviewed by Thomasen $^{2}$ and others. There have been many attempts to elucidate the underlying pathophysiology. The basic abnormality has been ascribed to hypersensitivity of the muscle membrane ${ }^{3}$ increased membrane fluidity ${ }^{4}$ and impairment of normal neurotropic influences exerted by motor neurones on muscle fibres. ${ }^{56}$ Quinine, steroids and procainamide have all been used for treatment of the myotonia with variable success. In 1959, Leyburn and Walton ${ }^{7}$ carried out a controlled trial comparing quinine, prednisolone and procainamide. They found reduction of myotonia with each drug in most cases, quinine being the least effective. There was little to choose between prednisolone and procainamide but with the latter some patients developed troublesome side-effects. Munsat ${ }^{3}$ achieved some slight improvement of myotonia with sodium phenytoin, which was well tolerated. The similarity in pharmacological properties of procainamide and disopyramide suggested that a trial of this drug was warranted.

\section{Methods}

\section{Subjects}

Ten patients, all of whom had suffered from myotonic dys-

Address for reprint requests: Dr M Finlay, Department of Experimental Medicine, Medical School, Beech Hill Road, Sheffield S10 2RX, UK.

Received 3 June 1981 and in revised form 5 December 1981.

Accepted 17 January 1982 trophy for between 4 and 21 years were included in the trial. There were seven men and three women aged between 31 and 59 years. All complained of weakness of their hands and the majority had noticed difficulty in relaxation of grip. Eight had also experienced impairment of gait. All exhibited bilateral ptosis, weakness and wasting of the masseters, temporalis, facial and sternomastoid muscles and wasting and weakness of the forearms and hands. The seven men had similar distal wasting and weakness of the legs but in two women the lower limbs were symptomatically normal; in the other woman, there was proximal weakness without wasting. Percussion myotonia was elicited in eight patients over the thenar eminence or tongue or both, and in two others myotonia was revealed by electromyography. Initial assessment was made without modification of current treatment. Two patients were taking procainamide and one of these was also receiving quinine; three were taking disopyramide, one deltacortril, and four were without medication. The patients were then asked to sustain maximum hand grip for three minutes, and afterwards to open the hand fully with fingers extended. The time taken to accomplish the latter task was recorded. In addition, an estimate of grip strength was made using an RAF Gripometer.

\section{Trial design}

Patients were divided at random into two groups; Group A received procainamide ( $250 \mathrm{mg} 6$ hourly for the first week, then $500 \mathrm{mg} 6$ hourly for the second week), Group B were given disopyramide $(100 \mathrm{mg} 8$ hourly for the first week, then $200 \mathrm{mg} 8$ hourly for the second week). After 14 days treatment, patients were re-assessed, treatment reversed between the two groups and a re-assessment made after a further 14 days. Procainamide hydrochloride (Pronestyl) was supplied in $250 \mathrm{mg}$ tablets and disopyramide base (Rythmodan) in $100 \mathrm{mg}$ capsules. Patients were allowed to recognise differences between the medications. Thus where procainamide or disopyramide had been taken pre- 
viously, the patients knew when they were allocated to their usual medication. Otherwise, the patients were unaware of the nature of the medication prescribed. Treatment was coded and the code known only to the dispensing pharmacist.

\section{Results}

Of the five patients who had not received procainamide or disopyramide previously, two were initially treated with procainamide followed by disopyramide (Table). On procainamide one patient (NT) had an improvement in grip strength of $10 \%$ but when changed to disopyramide, this reverted to its former level; nevertheless, whilst taking disopyramide he felt that his thumbs were less stiff, although hand opening was normal throughout. In the other patient $(\mathrm{AH})$ hand opening was also normal throughout and grip strength was unaffected by either medication. When the two patients who had been taking procainamide before the trial were changed to disopyramide, grip strength was unchanged in both but in one (GB), there was an improvement in hand opening of eight seconds and he felt generally less stiff whilst taking disopyramide.

Of the patients who had not received procainamide or disopyramide previously, three were initially treated with disopyramide followed by procainamide. On disopyramide, one patient (MR) had an improvement in grip strength of $5 \%$ and retarda- tion of hand opening detected before commencement of treatment was restored to normal. In a second patient (AM), however, grip strength was unchanged and moreover, retardation of hand opening increased by 5 seconds. The third patient (DP) had no change in either parameter but her legs felt stronger. When changed to procainamide, the first patient (MR) maintained the improvement in grip strength and hand opening. The second patient whose hand opening deteriorated on disopyramide (AM) showed a return to normal on procainamide. The third patient (DP) preferred disopyramide although neither medication affected her grip strength or hand opening. When the three patients who had been taking disopyramide before the trial were changed to procainamide, one (JP) felt more stiff on the smaller dose of procainamide and although she improved when the dose was increased, she generally preferred disopyramide. There was a slight deterioration in grip strength on procainamide but hand opening remained normal throughout. The other two patients could not tolerate procainamide, whilst treatment with disopyramide was well-tolerated and in one case (WS) had reduced stiffness although in the other (MP) no benefit had been noticed.

In general, apart from the one case referred to above, no difference was found in the response to the different doses used. In all, five patients developed side-effects on procainamide ranging

\section{Table Results in the two patient-groups}

(a) Results in patients who had received neither procainamide nor disopyramide previously and were initially allocated to procainamide.

(b) Results in patients who had received procainamide previously.

\begin{tabular}{|c|c|c|c|c|c|}
\hline & Patient & Treatment sequence & Hand opening & Grip strength & Subjective comments \\
\hline \multirow[t]{2}{*}{ (a) } & NT & 1. Procainamide & Normal throughout & $+10 \%$ & Thumbs less stiff on disopyramide \\
\hline & AH & 1. Procainamide & Normal throughout & No change & No benefit from either drug \\
\hline \multirow[t]{2}{*}{ (b) } & GB & 1. Procainamide & 15 seconds & No change & Generally less stiff on disopyramide \\
\hline & AW & $\begin{array}{l}\text { 2. Disopyramide } \\
\text { 1. Procainamide } \\
\text { 2. Disopyramide }\end{array}$ & $\begin{array}{l}\text { Normal throughout } \\
\text { Seconds }\end{array}$ & No change & No benefit from either drug \\
\hline
\end{tabular}

(a) Results in patients who had received neither procainamide nor disopyramide previously and were initially allocated to disopyramide. (b) Results in patients who had received disopyramide previously.

\begin{tabular}{|c|c|c|c|c|c|}
\hline \multirow[t]{3}{*}{ (a) } & MR & \multirow{6}{*}{$\begin{array}{l}\text { 1. Disopyramide } \\
\text { 2. Procainamide } \\
\text { 1. Disopyramide } \\
\text { 2. Procainamide } \\
\text { 1. Disopyramide } \\
\text { 2. Procainamide } \\
\text { 1. Disopyramide } \\
\text { 2. Procainamide } \\
\text { 1. Disopyramide } \\
\text { 2. Procainamide } \\
\text { 1. Disopyramide } \\
\text { 2. Procainamide }\end{array}$} & \multirow{3}{*}{$\begin{array}{l}10 \mathrm{~s} \rightarrow \text { normal } \\
\text { Normal } \\
10 \mathrm{~s} \rightarrow 15 \mathrm{~s} \\
15 \mathrm{~s} \rightarrow \text { normal } \\
\text { Normal throughout }\end{array}$} & $+5 \%$ & Improved by both drugs \\
\hline & AM & & & No change & Preferred procainamide \\
\hline & DP & & & No change & Preferred disopyramide \\
\hline \multirow[t]{3}{*}{ (b) } & JP & & Normal throughout & No change & More stiff on smaller dose of procainamide \\
\hline & WS & & \multicolumn{2}{|c|}{ Could not tolerate procainamide } & Greatly benefited by disopyramide \\
\hline & MP & & \multicolumn{2}{|c|}{ Could not tolerate procainamide } & No benefit from disopyramide \\
\hline
\end{tabular}


from abdominal pain and diarrhoea in the above two cases to sore throat, mild dyspepsia, constipation and transient facial swelling in four others. Six patients developed side-effects on disopyramide, five having either dryness of the mouth and blurring of vision or both. These symptoms were mild and principally noted on the maximum dose used. ${ }^{\circ}$ One other patient experienced mild heartburn.

\section{Discussion}

A cross-over trial of disopyramide and procainamide in the treatment of myotonic dystrophy has shown that disopyramide is as effective as procainamide and that it may be better tolerated. The response to treatment was nevertheless variable but the most striking improvements were seen where myotonia was more evident, as in delayed hand opening. Leyburn and Walton ${ }^{7}$ suggested that the individual variation in the response to drugs in patients with myotonic dystrophy was probably dependent on whether myotonia or weakness were the dominant disorder. It would seem likely that the best response would be obtained in the paramyotonias and in myotonia congenita in which myotonia predominates.

The precise mode of action of drugs that benefit myotonia remains obscure. Roses $\mathrm{et} \mathrm{al}^{4}$ showed that sodium phenytoin may correct membrane fluidity which is increased in myotonia. Munsat ${ }^{3}$ pointed out that various agents used successfully in the treatment of myotonic dystrophy including quinine, quinidine, procaine, procainamide, ACTH and steroids shared the property of membrane stabilisation, altering ratios of intracellular to extracellular ions or by some direct physicochemical effects. The site of action of phenytoin was similarly concluded to be the muscle itself by virtue of its effect on ion balance. Stabilisation of the polarised membrane of the muscle fibre preventing the repetitive firing of cardiac muscle is suggested to underlie the antiarrhythmic properties of quinine and procainamide. In a similar fashion, the fast repetitive action potentials associated with the after-contraction of myotonic muscle may also be prevented by membrane stabilisation. ${ }^{8}$ Disopyramide resembles these agents in its effects on cardiac muscle, its mechanism of action being explained in part by a quinidine-like effect on action potential duration. 9 This latter property is thus one shared by agents which are both effective in the treatment of myotonia. It is therefore tempting to ascribe the effect on myotonic muscle to membrane stabilisation through such modification of action potential. Nevertheless, differences between the properties of cardiac and skeletal muscle must be borne in mind in reaching such a conclusion.

I am grateful to Dr Peter Bradshaw for suggesting the project and for his encouragement.

\section{References}

' Steinert $\mathrm{H}$. Ueber das Klinische und anatomische. Bild des Muskelschwundes der Myotoniker. Dtsch Z Nervenh, 1909-10;37:38-104.

${ }^{2}$ Thomasen E. Myotonia (Thomsen's Disease). Paramyotonia and Dystrophia Myotonica. Copenhagen: Ejnar Munksgaard 1948.

${ }^{3}$ Munsat TL. Therapy of myotonia. A double-blind evaluation of diphenylhydantoin procainamide and placebo. Neurology (Minneap) 1967;17:359-67.

4 Roses AD, Butterfield A, Appel SH, Chestnut DB. Phenytoin and membrane fluidity in myotonic dystrophy. Arch Neurol 1975;32(8):525-8.

${ }^{5}$ McComas AJ, Campbell MJ, Sica REP. Electrophysiological study of dystrophia myotonica. $J$ Neurol Neurosurg Psychiatry 1971;34:132-9.

${ }^{6}$ McComas AJ, Sica REP, Toyonaga K. Incidence severity and time course of motor neurone dysfunction in myotonic dystrophy: their significance for understanding of anticipation. J Neurol Neurosurg Psychiatry 1978:41:882-93.

${ }^{7}$ Leyburn P, Walton JN. The treatment of myotonia: a controlled clinical trial. Brain 1959;82(1):81-91.

${ }^{8}$ Gerschwind N, Simpson JA. Procainamide in the treatment of myotonia. Brain 1955;78:81.

${ }^{9}$ Kus T, Sasynivk BI. Disopyramide phosphate: is it just otner quinidine? Can J Physiol Pharmacol 1978;56:326-31. 